\title{
THE ROLE OF PHONOLOGICAL AWARENESS IN EARLY CHILDHOOD READING IN ENGLISH
}

\author{
Bernard Nchindila \\ University of South Africa
}

This article supports the existence of the phonological rule that states, 'Delete an English word-final / $\mathrm{b} /$ when it occurs after $/ \mathrm{m} /$ ' in pronouncing English words. Examples that fall within the rule are given. However, the research postulates that the rule is incomplete because /b/ is silent even when it does not come at the end of certain English words. It is proposed that an interface of phonological, morphological and semantic elements influences the pronunciation of these words. The interdependent nature of these properties is such that, where all the elements are present, a change in phonological realities results in a change in meaning, even if morphological members are stable. The findings add fresh evidence to the body of knowledge in support of the role of phonological awareness in early reading acquisition at the level of breaking the reading code.

\section{INTRODUCTION}

Spelling in English involves representing words with sequences of symbols according to a number of conventions. Because it is in part systematic and in part an accident, spelling is highly problematic. Jamieson and Simpson in Snowling and Stackhouse (2006: 199), stress the problem as follows:

The conventionally correct spelling of a word may simply reflect its pronunciation but can also reflect its grammar, its meaning, the language from which the word was derived or any combination of these. To complicate matters further, some of these influences may be in conflict with one another. In fact spelling so frequently fails to reflect current pronunciation that basic soundsymbol correspondence is a relatively unreliable cue to accurate spelling.

Added to the problem explained above is the fact that the history of English has shown great shifts between the written word in Old English (OE) and modern pronunciation. As complex as the spelling-sound relationship in English is, the starting point of reading is the association of the letters to the sounds. But once this threshold is reached, a demand on the phonological skills of the learner is created. The learner then enters another phase of segmenting the speech stream into sounds and words. Such a phase requires underlying phonological abilities in a learner.

A phonological rule can be defined as a description of a systematic relationship between sounds (Kaisse, 1985). Phonological rules can function to describe a change in features, an 
addition of features, a deletion of segments, or indeed to reorder segments. The rule that this article focuses on is a deletion rule. Phonemic awareness is the understanding of different ways that oral language can be divided into smaller segments or the awareness of the fact that speech can be divided into smaller units such as syllables and phonemes (Adams, 1990). Research consistently shows that phonological awareness is a cognitive substrate of reading acquisition (e.g. Gallagher, Frith \& Snowling, 2000).

The phonological rule stating that, in the pronunciation of all English words ending in $/ \mathrm{mb} /$, $/ \mathrm{b} /$ is silent or deleted, leaving the $/ \mathrm{m} /$ sound is well documented (Fromkin \& Rodman, 1993). Using linguistic notation, the rule can be presented as:

In pronouncing English words,

$$
[b] \rightarrow[\phi] /[m]-\#
$$

Where:

' $\varnothing$ ' means 'empty', 'deleted', or 'is silent'

' $\rightarrow$ ' means 'becomes' or 'is'

's means 'in the context of' or 'environment'

'-' means 'after'

'\#' means 'word boundary' or 'end of a word' (after Crystal, 2000).

In words: in the pronunciation of English words, /b/ is deleted in an environment where /b/ comes after $/ \mathrm{m} /$ at the end of an English word.

It is asserted that this phonological rule is incomplete because, in all verb forms, adjectives ending in [-er], [-ing], or [-ed]; adverbs ending in [-ly] with meanings derived from adjectives ending in $[\mathrm{mb}]$ and nouns - including nouns ending in [-er] or [-ing] with meanings derived from verbs ending in $[\mathrm{mb}], / \mathrm{b} /$ is silent in the pronunciation of such words, even though $/ \mathrm{b} /$ does not occur at word boundary, whereas /b/ is sounded in other circumstances.

\section{THEORETICAL BACKGROUND}

There is ample evidence from research in support of the view that phonological abilities at kindergarten level are good predictors of reading success in the early school years (Bradley, 1989; O’Connor \& Jenkins, 1999).

A causal connection between phonologic skills and reading acquisition has been proven by studies showing that interventions designed to improve phonological awareness could facilitate the process of reading acquisition and lead to better reading performance in the early school years (Ball \& Blachman, 1988; Blachman, 1989; Bentin \& Leshem, 1993).

Research shows that phonological awareness is helpful in the development of the spelling skills of language learners (Gallagher, Frith \& Snowling, 2000; Muter, Hulme \& Snowling, 1997; Adams, 1990; Share, Jorm, Maclean \& Matthews, 1984), which, in turn, improve literacy skills in these learners (Rack, Snowling \& Olson, 1992; Goswami \& Bryant, 1990; Wagner \& Torgesen, 1987). Early research indicated that understanding a word's sound structure would enable a child to decode a word in print (Calfee, Lindamood \& Lindamood 1973; Fox \& Routh, 1975). Indeed, phonological awareness has been found to be the best 
single predictor of reading performance (Adams \& Bruck, 1995; Hecht, Burgess, Torgesen, Wagner \& Rashotte, 2000; Liberman, Shankweiler \& Liberman, 1989).

There is also evidence that the phonological properties of words affect morphological processing, and phonological aspects of morphological processing are related to reading achievement (e.g. Leong, 1989; Fowler \& Liberman, 1995; Champion, 1997; Singson, Mahoney \& Mann, 2000).

Leong (1989) and Champion (1997) contrasted good and poor readers. For Leong (1989), poor readers and spellers were slower at producing derived and base word forms than good readers or spellers, particularly when the words involved both phonological and orthographic changes from base to derived form. Champion (1997) established that, while poor readers differed from good readers in awareness of the semantic and syntactic aspects of derived forms, the differences were more pronounced in reading than in oral tasks.

Fowler and Liberman (1995) found that poor readers differed from good readers in the oral production of words that undergo phonological shifts and that students' sensitivity to morphologically complex words in an oral production task was related to their reading and spelling abilities. These studies provide evidence for the importance of phonology as it relates to morphological processing.

\section{DEVELOPING READING ABILITY: THE ROLE OF PHONOLOGICAL AWARENESS}

Reading is not an instinctive human ability such as speaking. Humans have not evolved in such a way that there is a reading centre in the brain (Meyer \& Rose, 1998; Wolf, 2008). In order to read, we have to adapt or train our brain to perform in ways it was not naturally designed to work (D’Arcangelo, 1999). Nevertheless, both oral and written languages are based on the same lexical, grammatical, syntactical and textual rules. The first thing that beginning readers have to experience is that written material is a representation of knowledge they already have, in other words, they have to learn to see the relation between meaning and print. However, while oral language usually is acquired without formal instruction, most children need explicit instruction in the process of learning to read. First, children have to develop the awareness that words are made up of sounds. Second, they have to develop the awareness that print represents these sounds. Third, they have to develop the understanding that the letters on the page represent these units of sound. Once they have reached this level of phonological awareness, they are ready to learn to read. For some children this is very difficult. The code-breaking strategy of identifying phonemes as units in the alphabetic code in particular, seems to be problematic for beginning readers because these phonemes can hardly be perceived as speech (Bertelson, 1987).

In addition to being able to break up spoken words into smaller units and to understand that letters represent sounds, several models of reading development have been proposed to describe the abilities and phases that characterise reading development (e.g., Frith, 1985; Chall, 1996). Frith, for example, distinguished three stages in learning to read words: the logographic stage, the alphabetic stage, and the orthographic stage. In the logographic stage children mainly use graphic features to read words without insight into the letter-sound correspondence. Children do not really read in this stage; they remember the features of the 
letter, the word or the logo. In the alphabetic stage, children learn to understand the principle of mapping graphemes onto phonemes to be able to decode both known and unknown words. Crucial in this stage is phonological awareness or the awareness of the fact that speech can be divided in smaller units such as syllables and phonemes (Adams, 1990). The orthographic stage distinguishes itself from the alphabetic stage by operating with bigger units, making use of spelling patterns, and being non-phonological.

Chall (1996) regarded reading acquisition as a developmental process involving qualitatively distinct phases. However, whereas Frith (1985) distinguished three stages centred around word recognition, Chall (1996) distinguished six stages of reading development from its beginnings to its most mature forms: Stage 0, the pre-reading stage (from birth to age 6); Stage 1, the decoding stage (ages 6 - 7); Stage 2, the confirmation and fluency stage (ages 7-); Stage 3, the 'reading for learning the new' stage (ages 9 - 14); Stage 4, the multiple viewpoints stage (ages 14 - 18); and Stage 5, the construction and reconstruction stage (ages 18 and above). According to Chall (1996), many people never reach the highest stage, and those who do typically take 20 years or even more to get there. Chall (1996) emphasised that the process of comprehension is practised in all of the stages, including the decoding stage.

In the United States of America, the National Reading Panel (NRP) report (National Institute of Child Health and Human Development (NICHD), 2000) not only emphasised the importance of developing teachers' content knowledge, but also identified the five components of reading instructions that research found to improve teachers' reading instruction and students' reading achievement. The five 'essential' components of reading instruction identified by the panel included:

- Phonemic awareness (the ability to recognise and distinguish the speech sounds of English)

- Phonics (an understanding of letter-sound correspondences)

- Fluency (the efficient decoding of words and connected text)

- Vocabulary (an understanding of the meaning of words and meaningful subunits of words)

- Comprehension (an understanding of the meaning of sentences, paragraphs and longer passages)

The work of the NRP indicates that explicit systematic instruction and guided practice in phonemic awareness and phonics may build a foundation for growth in fluency, which, in turn, supports the development of vocabulary and comprehension, the ultimate goal of reading instruction. The NRP has suggested that teachers require the capacity to identify students' levels of development in each of the five components of reading instruction, and to focus appropriate instruction on these components.

In a largely independent line of research, ample evidence has shown that an understanding of the sound structure of a language is fundamentally necessary for the successful acquisition of reading skill (e.g. Adams, 1990; Wagner \& Torgesen, 1987). That is, the ability to analyse, synthesise and manipulate phonemes and syllables must be mastered for a child to adequately learn precisely how these sounds correspond to the shapes that are known as letters. Empirical evidence for this has come from the fact that preliterate children who have better knowledge of the sound structure of a language are quicker to learn to read (Wagner \& Torgesen, 1987), and that both the absolute level (Share, Jorm, MacLean, \& Mathews, 1984) 
and rate of acquisition (Byrne, Fielding-Barnesley \& Ashley, 2000) of early phonological awareness skills are excellent predictors of elementary reading skills.

Wagner and Torgesen (1987) found that individual differences in phonological awareness persisted in explaining reading abilities each year from kindergarten through fourth grade, whereas the relationships between reading and other skills faded with development. In fact, kindergarten phonological awareness is known to be a better predictor of teenage reading ability than is kindergarten reading skill (MacDonald \& Cornwall, 1995). Studies of twins have suggested that phonological skills have both genetically heritable and environmentally influenced components (Fisher \& DeFries, 2002) and a deficit in phonological processing is now believed to be the primary core deficit in developmental dyslexia, a reading disability in which children exhibit difficulty in accurately or fluently reading at age-appropriate levels (Bradley \& Bryant, 1983). According to McCandliss and Noble (2003), this phonological impairment is reflected in the dysfunction of what they term left perisylvian cortical regions during reading tasks. Importantly, experimental manipulations in which reading-disabled children were exposed to both phonological skill training and explicit instruction in lettersound correspondence rules have resulted in improved reading ability, relative to various reading-disabled control groups (Foorman, Francis, Novy \& Liberman, 1991; Wagner \& Torgesen, 1987), suggesting that phonological skill is not merely associated with reading, but actually plays a causal role in the development of reading. Phonological awareness has been associated repeatedly with the ability to decode both words and non-words, and, to a lesser extent, with reading comprehension ability (e.g. Share, 1995).

\section{THE SOUTH AFRICAN CONTEXT}

Reading achievement among school children in South Africa has been dismal. For example, when South Africa participated in the Progress in International Reading Literacy Study (PIRLS) of 2006, South African children came last out of the 40 countries. As Taylor and Yu (2008: 1) write,

South Africa's mean reading score is the lowest out of the 40 participating countries in PIRLS 2006. This result is in line with a similar international survey - TIMMS2 2003 - where South Africa recorded the lowest mean scores in both mathematics and science, out of the 50 participants.

PIRLS is managed by the International Association for the Evaluation of Educational Achievement (IEA). The IEA is an independent, international organisation of national research institutions and governmental research agencies. It has conducted over 20 international surveys since 1958 and several of these are now undertaken in regular cycles. The first PIRLS survey was conducted in 2001 and the second was in 2006 (Whetton, Twist \& Sainsbury, 2007). The two reading purposes assessed in PIRLS 2006 were Literary and Informational. These processes are further subdivided as retrieving and straightforward inferencing and interpreting, integrating, and evaluating information. Clearly, these reading purposes are higher and require higher-order skills than breaking the reading code that phonological awareness demands. However, the point has to be made that, although mastery of lower-order reading skills is not sufficient for full reading comprehension to take root, mastery of higher-order reading skills depends on mastery of lower-order skills. 
Various reasons for poor reading achievement in South Africa have been advanced, chief of which are lack of resources and lack of English language teaching expertise. For many years, South Africa has been administering instruction in the mother tongue of learners for most of whom English is not a mother tongue and English has been introduced in Grade 3 in public schools. After fifteen years of democratic governance, South Africa appears to have reached the conclusion that this approach has not led to the required academic benefits for Black children who use African languages as their medium of instruction until Grade 3. Reacting to the poor Grade 12 matriculation results of 2010, Angie Motshekga, Minister of Basic Education in South Africa, has argued that earlier exposure to English would better prepare the students for their final school examinations. Following the research findings that indicated that exposing children to languages at a young age was beneficial, a team appointed by the Minister in 2009 to review the implementation of the National Curriculum Statement

strongly recommended that English, as a first additional language, be introduced as a fourth subject from Grade R to Grade 3 from 2011 (Sunday Times 10 January, 2010:4).

Introducing English as early as possible in South African schools is to be welcomed because most of the learners are ESL learners who need sufficient contact with English.

The problem for learners of English as an academic language is the lack of correspondence between spelling and sound in English. According to Ellis and Tomlinson (1988: 96), 'most of the Asian and African languages that were given a written form relatively recently have correspondence between spelling and sound. Most of the African speakers of English fall in this category'. This implies that speakers of English from this background especially can experience pronunciation and spelling problems, since most of their first languages have spelling-sound correspondence, which is not the case in the English language. By implication, a native speaker of English does not experience this particular problem, since the speaker does not have a basis for generalising the sound-spelling correspondence rule. Although the position articulated here is quite correct, there may be evidence of lack of spelling-sound correspondence in written African languages. In this respect, to generalise the problem of pronouncing / $\mathrm{mb} /$ English word endings in both speakers of English as a first language and English as a second language, further research is necessary. Therefore, from the onset, the present study should be looked at as an initial attempt in addressing problems of reading at early stages of learning and not as a panacea.

\section{THE RESEARCH DESIGN}

The approach to the study was exploratory. Relying on the work of Fromkin and Rodman (1993) with respect to the phonological rule: Delete an English word-final /b/ when it occurs after $/ \mathrm{m} /$ in pronouncing English words, I collected English words with $/ \mathrm{mb} /$ endings using the Oxford Advanced Learner's Dictionary (2010) and the Longman Dictionary of Contemporary English (2009). Data were collected and analysed in a qualitative design. In this respect, the corpus is not exhaustive, nor is any statistical significance claimed. Therefore the findings are to be interpreted within the limitations of a qualitative research orientation. 


\section{PROCEDURE}

Testing the phonological rule: Delete an English word-final $/ \mathrm{b} /$ when it occurs after $/ \mathrm{m} / \mathrm{in}$ pronouncing English words beyond word boundary

\section{Pronouncing English verbs ending in $/ \mathrm{mb} /$}

Example 1: Comb, combed, combing

Using phonetic symbols, the words can be transcribed as:

Table 1:

\begin{tabular}{|l|l|l|}
\hline / kəum / & / kəumd / & / kəumIy / \\
\hline
\end{tabular}

Table 1 shows that /b/ is silent even when it does not occur at word boundary.

Example 2: succumb, succumbed, succumbing

Using phonetic symbols these words are transcribed and presented in Table 2.

Table 2:

\begin{tabular}{|l|l|l|}
\hline /sək^m / & / sək^md / & sək^mIy/ \\
\hline
\end{tabular}

Table 2 shows that $/ \boldsymbol{b} /$ is silent in English verbs ending in $/ \mathrm{mb}$ / beyond word boundary.

\section{Pronouncing English nouns ending in / $\mathrm{mb} /$ :}

Table 3:

\begin{tabular}{|l|l|l|l|l|l|l|}
\hline lamb & thumb & bomb & comb & imb & womb & tomb \\
\hline $\mathrm{lam} /$ & $/ \theta \wedge \mathrm{m} /$ & $/ \mathrm{bDm} /$ & $/ \mathrm{k} \partial \mathrm{m} /$ & $/ \mathrm{lmm} /$ & $/ \mathrm{wu}: \mathrm{m} /$ & $/ \mathrm{tu}: \mathrm{m} /$ \\
\hline
\end{tabular}

Table 3 shows that $/ b /$ is silent in English nouns ending in $[m b]$. The same holds true for the plurals of these nouns.

For tense purposes, third person singular with a present simple verb, past simple regular -ed, and participle -ing endings, it is important to confirm that $/ b /$ is silent in these situations because most dictionaries do not go as far as making this conclusion, even though they transcribe these words phonetically without $/ b /$ (See, for example, the Oxford Advanced Learner's Dictionary (2010) and the Longman Dictionary of Contemporary English). 
Examples are illustrated in Table 2 below.

\begin{tabular}{|c|c|c|c|}
\hline Verb & $\begin{array}{l}\text { Third person singular } \\
+ \text { present simple }\end{array}$ & Present Participle & Past simple regular \\
\hline 1. Bomb & Bombs & Bombing & Bombed \\
\hline$/ \mathrm{bDm} /$ & /boms/ & /bDmIy/ & /bDmd/ \\
\hline 2. Comb & Combs & Combing & Combed \\
\hline /kəum/ & /kəums/ & /kəumIy/ & /kəumd/ \\
\hline 3. Plumb & Plumbs & Plumbing & Plumbed \\
\hline / pl^m/ & $/ \mathrm{pl} \wedge \mathrm{ms} /$ & /pl^mIn/ & /pl^md/ \\
\hline
\end{tabular}

Pronouncing nouns ending in /er/ derived from the meanings of words ending in $/ \mathrm{mb} /$

Table 4:

\begin{tabular}{|l|l|}
\hline Noun derived from verb ending in $[\mathrm{mb}]$ & Verb ending in $[\mathrm{mb}]$ \\
\hline 1. Climber & Climb \\
\hline /klaimər/ & /klaIm/ \\
\hline 2. Bomber & Bomb \\
\hline /bDmər/ & $/ \mathrm{bDm} /$ \\
\hline 3. Plumber & $\mathrm{plumb}$ \\
\hline /pl^mər/ & $/ \mathrm{pl} \wedge \mathrm{m} /$ \\
\hline
\end{tabular}

The table shows that the nouns that are formed are derived from the meanings of their verbs, and that, in all circumstances, $/ b /$ is silent because it is joined to the left of the syllable forming the verb that ends in $[\mathrm{mb}]$. The right-hand syllable $[\mathrm{er}]$ joins $[\mathrm{m}]$ since $/ \mathrm{b} /$ is silent in every verb form when the verb is suffixed for tense purposes.

On the other hand, a noun ending in /er/ whose meaning is not derived from a verb ending in $/ \mathrm{mb} /$ maintains the $/ \mathrm{b} /$ sound in its pronunciation:

Example 6

1. A number does not 'numb'

2. A lumber does not 'lumb'

3. Timber does not 'timb'

4. Slumber does not 'slumb'

In all the examples above, $[b]$ is joined to the right of the syllable to form the syllable [ber], leaving the left-hand syllable free; $/ b /$ is therefore pronounced because the syllable to the left does not end in $[\mathrm{mb}]$. 
Pronouncing adjectives ending in $/ m b /$ :

Table 5:

\begin{tabular}{|c|c|c|}
\hline 1. Dumb & 2. Numb & 3. Aplomb \\
\hline$/ \mathrm{d} \wedge \mathrm{m} /$ & $/ \mathrm{n} \wedge \mathrm{m} /$ & $/$ /əplom/ \\
\hline
\end{tabular}

Table 5 shows that $/ \mathrm{b} /$ is silent when pronouncing adjectives that end in $/ \mathrm{mb} /$.

Pronouncing nouns derived from meanings of adjectives ending in $/ \mathrm{mb} /$ :

Table 6:

\begin{tabular}{|c|l|}
\hline 1. Numbness & Dumbness \\
\hline$/ \mathrm{n} \wedge \mathrm{mnIs} /$ & $/ \mathrm{d} \wedge \mathrm{mnIs} /$ \\
\hline
\end{tabular}

Table 6 shows that $/ \mathrm{b} /$ is silent when nouns with meanings derived from adjectives ending in $/ \mathrm{mb} /$ are pronounced.

Pronouncing adverbs derived from meanings of adjectives ending in $/ \mathrm{mb} /$

Table 7:

\begin{tabular}{|c|l|}
\hline Numbly & Dumbly \\
\hline /n^mlI/ & $/ \mathrm{d} \wedge \mathrm{mlI} /$ \\
\hline
\end{tabular}

In Table $7, / \mathrm{b} /$ is shown to be silent when adverbs derived from meanings of adjectives ending in $/ \mathrm{mb} /$ are pronounced.

Pronouncing adjectives ending in $/ \mathrm{mb} /$ in comparative and superlative forms

Table 8:

\begin{tabular}{|l|c|l|}
\hline Numb & Number & Numbest \\
\hline$/ \mathrm{n} \wedge \mathrm{m} /$ & $/ \mathrm{n} \wedge \mathrm{m} ə r /$ & $/ \mathrm{n} \wedge \mathrm{mIst} /$ \\
\hline
\end{tabular}

Table 8 shows that $/ \mathrm{b} /$ is silent when adjectives ending in $/ \mathrm{mb} /$ in comparative and superlative forms are pronounced. 


\section{PERMISSIBLE MORPHEMES BEYOND WORD BOUNDARY}

Data suggest that the permissible morphemes beyond the word boundary are $-\mathrm{s}$, for regular plural forms and tense, -ed and -ing for tense and adjectives, -ing, and -er for nouns and adjectives, and -ly for adverbs, as long as the semanticity of the new word is derived from the one that ends in the $[\mathrm{mb}]$ morpheme.

\section{Example 7:}

'iamb' is pronounced as /aræm/ whereas 'iambic' is pronounced as /aræmbIk/.

On the basis of what is postulated, it can logically be concluded that there is a semantic relationship between 'iamb' and 'iambic' since 'iambic' is an adjective derived from the noun 'iamb'. However, the morpheme -ic is not one of the permissible morphemes beyond word boundary. Morphologically, therefore, 'iambic' does not fall in the category of English words where $/ \mathrm{b} /$ is deleted beyond word boundary. Consequently $/ \mathrm{b} /$ in 'iambic' is sounded.

Because of this, 'iamb' is sometimes pronounced as /aræmb/ with a /b/ sound (e.g. Oxford Advanced Learner's dictionary, 2010: 241). However, the variation in pronunciation is a matter requiring further research.

Since the word, 'number' has been dealt with under nouns, the word, 'number' as an adjective is pronounced without the $/ b /$ sound because, as a comparative adjective, it is derived from 'numb', an adjective ending in the $/ \mathrm{m} /$ sound. As a noun, the $/ \boldsymbol{b} /$ in 'number' is pronounced since the meaning is not derived from the root word 'numb'. In this respect, the root word of noun 'number' does not end in $/ \mathrm{mb} /$.

Similarly, in the pronunciation of the words 'bombard' 'bombarded' and 'bombarding', /b/ is pronounced because the root word 'bombard' does not end in the morpheme -mb. Although the meaning of this word is similar to the word 'bomb' the word 'bombard' exists as a verb not ending in the $-\mathrm{mb}$ morpheme and is inflected for tense and adjectival purposes at a different boundary from the word 'bomb'.

\section{CENTRALITY OF PHONOLOGICAL, MORPHOLOGICAL AND SEMANTIC UNITS}

Based on the analysis of the word 'bombard' it can be argued that, in the appreciation of the phonological rule 'delete a word-final $/ \mathrm{b} /$ when it occurs after $/ \mathrm{m} /$, phonological, morphological and semantic properties play an important role beyond word boundary. The convergence of phonological, morphological and semantic properties in the extension of this rule is suggestive that the absence of one of these properties is enough to invalidate the rule. The example in the analysis of the word 'number', however means that, where all the properties are present, a change in phonological realities results into a change in meaning, even if morphological members are stable. This brings into focus the question of intelligibility, because the meaning of the word 'number' depends on its pronunciation.

As Kaisse (online) writes about the cyclic nature of phonological and morphological interaction, 
The common core of the 'direct' and the 'indirect' view of phonology/morphology interaction is that cycles are the organizing principle for the application of lexical phonological rules. A further property of lexical rules is that their application is governed by the S[TRICT] C[YCLE] C[ONDITION], one of the most important principles of Lexical Phonology. The essence of the SCC is that feature-changing (applications of) cyclic phonological rules apply only in derived environments. The environment may be derived either morphologically or phonologically. In the former case, a new structure is derived from the operation of a morphological rule. In the latter, it results from a phonological rule.

What Kaisse states above is consistent with the findings of Ben-Dror, Bentin and Frost (1995) where evidence of the importance of semantic, phonologic, and morphologic skills in the reading of disabled and normal children was supplied.

The phonological rule excludes proper names because the sources of proper names are not always known. This rule therefore applies only to the English words.

\section{HOW THE RULE CAN BE USED}

As stated in the literature, this phonological rule feeds into phonological awareness which is directly linked to literacy skills. Since the literature suggests that students' sensitivity to morphologically complex words is related to their reading and spelling abilities, teaching pronunciation of the words covered in this phonological rule can be rewarding to the learner.

Because of the fact that the English language is said to have an irregular spelling-sound correspondence, and the issue at hand has been confused before, learners would understand this exception better by following a formula covering all its subtleties, as presented in this article. Whereas Crystal (2000: 217) classifies the pronunciation of some of these words ending in /mb/ as irregular, Fromkin and Rodman (1993: 261) argue that the pronunciation of such words is regular because it can be accounted for. Because the findings from this research are consistent with those of Fromkin and Rodman, the study concludes that the pronunciation of such words is indeed regular, a point that should necessarily compel Crystal's (2000) work to be brought in line for his revised editions.

The problem of the spelling-sound correspondence can be approached from different angles. One can approach it from the teacher's point of view or from the learner's point of view. As this contribution draws on phonetic skills, it is proposed that teaching should be by way of reading and listening. It is suggested that learners should first see the word and hear it before they say it, paying attention to the meaning derived from the root word. Against this background it can be suggested that English words such as lamb, thumb, bomb and comb, can be introduced early in the school year. As vocabulary items, these common words are a good initiation to the bigger picture. Once the students see the words they should hear the pronunciation and then say them. If the teacher can take advantage of the 'Mary had a little lamb' song as a deliberate agenda to introduce awareness of this phonological rule at nursery school level, the seed will have been planted. If the Catholic priest can preach this through the Eucharist in: 'this is the Lamb of God who takes away the sins of the world.... happy are we who are called to His supper', it will be a successful Sunday school. After all, in some remote parts of Africa, the first contact learners of English as a foreign language have had has been with the servants of God! 
At a higher level, there is scope for teaching the rule with exemplification using parts of speech and tense patterns, as proposed here, so that learners can confidently deal with this issue. While it might be argued that linguistic notation should not be introduced too early in learning, this phonological rule has a clearly argued wording that is reliable enough. Learners can therefore relate to the rule without hindrance of linguistic notation.

\section{CONCLUSION AND LIMITATIONS OF THE STUDY}

Research drawn on for the theoretical background supports the view that poor readers and spellers are slower at producing derived and base word forms than good readers or spellers, especially when the words involve both phonological changes from base to derived form. The phonological rule discussed in this article covers the issue of the change of word base to derived form. Similarly, research suggests that poor readers differ from good readers in awareness of the semantic and syntactic aspects of derived forms in reading tasks. The phonological rule discussed here addresses the issue of semantic properties. That pronunciation, word formation and meaning have converged in this study should especially be seen as a point of strength because teaching reading in most African countries has been criticised for being mere look and say (Williams, 1993) with very little attention paid to meaning. An effort that contributes to reading comprehension skills in English to this effect should therefore be encouraged. This research is an empirical contribution in that direction.

A limitation of this study is that it is based on a limited sample drawn through a qualitative research orientation from two dictionaries, namely the Oxford Advanced Learner's Dictionary and Longman Dictionary of Contemporary English. Further studies could look at ways of testing the rule on an empirical sample of students early in the school year in a quantitative design. As the literature concerning the theoretical background of the present article shows, studies aimed at establishing correlations between phonemic awareness and reading achievement have been carried out in the United States of America - a rich context of speakers of English as a first and as a second language. In this respect, an important contribution made through this article has been to bring to the surface the relationship between early reading achievement and phonological awareness with respect to the pronunciation of English word endings in /mb/ beyond word boundary. Future research in Africa and other similar contexts where English is used as the major language of reading literacy should focus on quantitative studies that deal with correlations between reading achievement and phonological awareness for specific ages and grades of school children. Such studies would assist in presenting demographic differences in the learning patterns of children being raised in poverty in African contexts who may have limited access to Received Pronunciation (RP). They would also firmly assert the validity and reliability of the phonological rule and the extent to which phonological awareness affects reading achievement.

\section{REFERENCES}

ADAMS, MJ. 1990. Beginning to read: Thinking and learning about print. Cambridge, MA: The MIT Press.

ADAMS, MJ \& M BRUCK.1995. Resolving the great debate. American Educator, 19:7-20.

BALL, E \& B BLACHMAN. 1988. Phoneme segmentation training: Effect on reading readiness. Annals of Dyslexia, 38:208-225. 
BLACHMAN, B. 1989. Phonologic awareness and word recognition: Assessment and intervention. In A.G. Kamhi \& H.W. Catts (eds), Reading disabilities: A developmental language perspective. Boston, MA: College Hill. 133-158.

BRADELY, L. 1989. Predicting learning disabilities. In J.J. Dumont \& H. Nakken (eds), Learning disabilities: Cognitive, social and remedial aspects (pp. 1-17). Amsterdam: Swets \& Zeitlinger.

BRADLEY, L \& PE BRYANT, 1983. Categorising sound and learning to read: A causal connection. Nature 301:419-421.

BEN-DROR, I, S BENTIN\& R FROST. 1995. Semantic, phonologic, and morphologic skills in reading disabled and normal children: Evidence from perception and production of spoken Hebrew. Reading Research Quarterly, 30 (4):876-893.

BENTIN, S \& H LESHEM. 1993. On the interaction of phonologic awareness and reading acquisition: It's a two-way street. Annals of Dyslexia, 43:2-29.

BERTELSON, P. 1987. The Onset of Literacy. Cambridge, Ma: The MIT Press.

BYRNE, B, R FIELDING-BARNSLEY \& L ASHLEY. 2000. Effects of preschool phoneme identity training after six years: Outcome level distinguished from rate of response. Journal of Educational Psychology, 92(4), 659-667.

CALFEE, R, C LINDAMOOD \& P LINDAMOOD. 1973. Acoustic-phonetic skills and reading - Kindergarten through twelfth grade. Journal of Educational Psychology, 64:293-298.

CHAMPION, AH. 1997. Knowledge of suffixed words in reading and oral language contexts: A comparison of reading disabled and normal readers. Annals of Dyslexia, 47:29-55.

CHALL, JS. 1996. Learning to read: The great debate. New York: McGraw-Hill.

CRYSTAL, D. 2000. The Cambridge Encyclopedia of Language. Cambridge: Cambridge University Press.

D'ARCANGELO, M.1999. Learning about learning to read: A conversation with Sally Shaywitz. Educational Leadership, 57:26-31.

ELLIS, R \& B TOMLINSON. 1988. Teaching secondary English, A guide to the teaching of English as a second language. London: Longman group.

FELDMAN, LB. (ed). 1995. Morphological aspects of language processing. Hillsdale, NJ: Lawrence Erlbaum.

FISHER, SE \& JC DeFRIES. 2002. Developmental dyslexia: Genetic dissection of a complex cognitive trait. Nature Reviews Neuroscience, 3:767-780.

FOORMAN, BR, DJ FRANCIS, D NOVY \& D LIBERMAN. 1991. How letter-sound instruction mediates progress in first grade reading and spelling. Journal of Educational Psychology, 83:456-469.

FOWLER, AE \& IY LIBERMAN. 1995. The role of phonology and orthography in morphological awareness. In LB Feldman (ed), Morphological aspects of language processing. Hillsdale, NJ: Lawrence Erlbaum Associates. 157-188. 
FOX, B \& DK ROUTH. 1975. Analyzing spoken language into words, syllables, and phonemes: A developmental study. Journal of Psycholinguistic Research, (4):331-342.

FRITH, U. 1985. Beneath the surface of developmental dyslexia. In K. Patterson, M. Coltheart \& J. Marshall (eds), Surface Dyslexia (pp.301-330). London: Lawrence Erlbaum Associates Ltd.

FROMKIN, V \& R RODMAN. 1993. An introduction to language. Holt: Rinehart and Winston.

GALLAGHER, A, U FRITH \& MJ SNOWLING. 2000. Precursors of literacy delay among children at genetic risk of dyslexia. Journal of Child Psychology and Psychiatry and Allied Disciplines, 41:202-213.

GOSWAMI, U \& PE BRYANT. 1990. Phonological skills and learning to read. Hillsdale, NJ: Lawrence Erlbaum.

HECHT, SA, SR BURGESS, JK TORGESEN, RK WAGNER \& CA RASHOTTE. 2000. Explaining social class differences in growth of reading skills from beginning kindergarten through fourth-grade: The role of phonological awareness, rate of access, and print knowledge. Reading and Writing: An Interdisciplinary Journal, 12:99-127.

JAMIESON, C \& S SIMPSON. 2006. Spelling: Challenges and strategies for the dyslexic learner and the teacher. In Snowling, MJ \& J Stackhouse (eds), Dyslexia, Speech and Language: A Practitioner's Handbook. London: Whurr publishers. 198-228.

KAISSE, E. 1985. Connected speech. The interaction of syntax and phonology. New York: Academic Press.

KAISSE, E. 2010. Lexical phonology [Online]. Available: http://www.ling.fju.edu.tw/phono/le.htm [2010, December 10].

LEONG, CK. 1989. Productive knowledge of derivational rules in poor readers. Annals of Dyslexia, 39:94-115.

LIBERMAN, IY, D SHANKWEILER \& AM LIBERMAN. 1989. The alphabetic principle and learning to read. In D Shankweiler, D \& IY Liberman (eds), Phonology and reading disability: Solving the reading puzzle. IARLD Monograph Series, Ann Arbor, MI: University of Michigan Press

LONGMAN DICTIONARY OF CONTEMPORARY ENGLISH. 2009. London. Longman Education.

MACDONALD, GW \& A CORNWALL. 1995. The relationship between phonological awareness and reading and spelling achievement eleven years later. Journal of Learning Disabilities, 28:523-527.

McCANDLISS, BD \& KG NOBLE. 2003. The development of reading impairment: A cognitive neuroscience model. Ment. Retard. Dev. Disabil. Res. Rev. 9(3):196-204.

MEYER, A \& DH ROSE. 1998. Learning to read in the computer age. Cambridge, MA: Brookline Books.

MUTER, V, C HULME \& M SNOWLING. 1997. The phonological abilities test. London: The Psychological Corporation.

NICHD, NATIONAL INSTITUTE OF CHILD HEALTH AND HUMAN DEVELOPMENT. 2000. Teaching children to read: An evidence-based assessment of the scientific research literature on reading and its implications for reading instruction: Reports of 
the subgroups (Report of the National Reading Panel, NIH Publication No. 00-4754). Washington, DC: U.S. Government Printing Office.

O'CONNOR, R \& J JENKINS. 1999. Prediction of reading disabilities in kindergarten and first grade. Scientific Studies of Reading, 3:159-197.

OXFORD ADVANCED LEARNER'S DICTIONARY. 2010. Oxford. Oxford University Press.

RACK ,JP, MJ SNOWLING \& RK OLSON. 1992. The nonword reading deficit in developmental dyslexia: A review. Reading Research Quarterly. 27:28-53.

SHARE, DL. 1995. Phonological recoding and self-teaching: Sine qua non of reading acquisition. Cognition 55, 151-218.

SHARE, DL, AF JORM, R MACLEAN \& R MATTHEWS. 1984. Sources of individual differences in reading acquisition. Journal of Educational Psychology, 76(6):13091324.

SINGSON, M, D MAHONEY \& V MANN. 2000. The relation between reading ability and morphological skills: Evidence from derivational suffixes. Reading and Writing: An Interdisciplinary Journal, 12:219-252.

SNOWLING, M \& J STACKHOUSE. 2006. Dyslexia. Speech and language. London. Whurr Publishers.

SUNDAY TIMES (SA). 2010.10 January. Johannesburg: AVUZA.

TAYLOR, S \& D YU. 2008. The importance of socio-economic status in determining educational achievement in South Africa [Online]. Available: http://www.commerce.uct.ac.za/research_units/dpru/Conference2008/Conference2008 Papers/StephenTaylor_Socio_Economic_Status.pdf [2010, January 10].

WAGNER, RK \& JK TORGESEN. 1987. The nature of phonological processing and its causal role in the acquisition of reading skills. Psychological Bulletin, 30:73-87.

WHETTON, C, L TWIST \& M SAINSBURY. 2007. Measuring standards in primary English: The validity of PIRLS - a response to Mary Hilton. British Educational Research Journal, 33(6):977-986.

WILLIAMS, E. 1993. Report on reading in English in primary schools in Zambia (Education Research Report, Serial Number 5) London: Overseas Development Administration.

WOLF, M. 2008. Proust and the squid: The story of science and the reading brain. London: Icon Books.

\section{BIOGRAPHICAL NOTE}

Bernard Nchindila does his academic work at Unisa in the Department of English Studies. His research interests include reading literacy in ESL contexts and English for academic purposes.

E-mail address: nchinbm@unisa.ac.za 